\title{
Drug treatment in attention deficit disorder: a survey of professional consensus
}

\author{
Kapil Sayal and Eric Taylor
}

\begin{abstract}
The strong recent public interest in attention deficit disorder and lits drug treatment has led to the need for, and development of, guidelines for clinical practice. As a first step in this process our aim was to ascertain the current level of professional consensus on certain points regarding the use of medication in attention deficit disorder. Although a high level of consensus was found in relation to indications and prescribing issues, opinion was divided on details of how the treatment should be dellvered - including the role of paediatricians, and the use of psychological treatments.
\end{abstract}

The essential characteristics of hyperkinetic disorder are persistent traits of severe and pervasive inattentiveness, overactivity and impulsiveness, beginning in the first five years of life (Taylor \& Hemsley, 1995). Affected children are a subgroup of those who meet the broader criteria for attention deficit/hyperactivity disorder (ADHD) in DSM-IV (American Psychiatric Association, 1994). British and American authorities advocate a combination of pharmacological, psychological and educational approaches (Sandberg, 1996). Nevertheless, drug treatment for ADHD or hyperkinetic disorder is still used infrequently in child mental health practice in the UK. If this is due to unfamiliarity with the treatment, we would expect experts to have a more positive appraisal of medication.

\section{The study}

A 16-item questionnaire consisting of statements about drug treatment that have been made in various places (e.g. British National Formulary; Consumers' Association, 1995; Taylor \& Hemsley, 1995) was designed. This covered areas including: the role of various professionals in the initiation and continuation of prescribing; associated psychological treatments; practical issues regarding dosage amount and regimes; age limits; and indications for drug use. A five-item response scale was used to indicate degree of agreement or disagreement. Further comments were encouraged. The questionnaire was sent to 24 professors or consultants in child and adolescent psychiatry who have a known interest in the treatment of $\mathrm{ADHD}$ and hyperkinetic disorder.

\section{Findings}

There was a $100 \%$ response rate. The results are presented in three main areas: high consensus statements, practice issues, and prescribing issues.

Table 1 refers to high consensus statements. There was marked agreeement (96\%) that methylphenidate is a useful treatment in children with a diagnosis of hyperkinetic disorder. Additionally there was general agreement $(83 \%)$ that methylphenidate is helpful for some children with ADHD who do not meet the criteria for hyperkinetic disorder. However, it was generally felt $(75 \%)$ that a trial of methylphenidate was not indicated in all children with a diagnosis of ADHD even if there are no contraindications. It was agreed $(83 \%)$ that other drug treatment should be given if a trial of methylphenidate fails in a child with ADHD. In terms of age ranges it was agreed that it may be appropriate to use methylphenidate in children below the age of 6 years $(79 \%)$ and above the age of 13 years (92\%). Respondents referred to the alternative use of dexamphetamine in the younger age group. In teenagers the issue of starting as a new treatment, with the associated risk of misuse, was also identified.

Table 2 refers to practice issues. There were conflicting opinions regarding different professionals' roles in prescribing methylphenidate; $58 \%$ of respondents agreed that methylphenidate treatment should only be initiated by child psychiatrists, while $54 \%$ agreed that paediatricians should be able to initiate it. This apparent contradiction was clarified by written comments. Several people considered that the rule should be for child psychiatrists to initiate, but that exceptionally paediatricians should do so (i.e. when the paediatrician has special training and experience). Respondents agreed $(88 \%)$ that general practitioners should be able to continue 
Table 1. High consensus statements $(n=24)$

\begin{tabular}{llll}
\hline Statement & Agree & Disagree & Don't know \\
\hline $\begin{array}{l}\text { Methylphenidate is useful } \\
\text { in hyperkinetic disorder }\end{array}$ & $23(96 \%)$ & 0 & $1(4 \%)$ \\
$\begin{array}{c}\text { Methylphenidate is helpful } \\
\text { for some children with ADHD }\end{array}$ & $20(84 \%)$ & $2(8 \%)$ & $2(8 \%)$ \\
$\begin{array}{l}\text { All ADHD children should have } \\
\text { a methylphenidate trial }\end{array}$ & $6(25 \%)$ & $18(75 \%)$ & 0 \\
$\begin{array}{c}\text { Trial of other drugs in ADHD } \\
\text { if methylphenidate fails }\end{array}$ & $20(83 \%)$ & $1(4 \%)$ & $3(13 \%)$ \\
$\begin{array}{l}\text { May be appropriate to use under } \\
\text { the age of } 6 \text { years }\end{array}$ & $19(79 \%)$ & $3(13 \%)$ & $2(8 \%)$ \\
$\begin{array}{l}\text { May be appropriate to use over } \\
\text { the age of } 13 \text { years }\end{array}$ & $22(92 \%)$ & $1(4 \%)$ & $1(4 \%)$ \\
\hline
\end{tabular}

Table 2. Methylphenidate practice issues $(n=24)$

\begin{tabular}{|c|c|c|c|}
\hline Statement & Agreo & Disagree & Don'f know \\
\hline $\begin{array}{l}\text { Should only be initiated by child psychiatrists } \\
\text { Paediatricians should be able to initiate it } \\
\text { General practitioners continuing } \\
\text { prescribing until next review }\end{array}$ & $\begin{array}{l}14(58 \%) \\
13(54 \%) \\
21(87 \%)\end{array}$ & $\begin{array}{r}10(42 \%) \\
9(38 \%) \\
3(13 \%)\end{array}$ & $\begin{array}{l}0 \\
2(8 \%) \\
0\end{array}$ \\
\hline $\begin{array}{l}\text { Should only be used where } \\
\text { psychological theraples have failed }\end{array}$ & 6 (25\%) & 18 (75\%) & 0 \\
\hline $\begin{array}{l}\text { Should only be used as an adjunct } \\
\text { to psychological therapies }\end{array}$ & 13 (54\%) & 11 (46\%) & 0 \\
\hline
\end{tabular}

methylphenidate prescribing and monitoring until the next review appointment, once the decision to treat had been made by a specialist.

A further area of differing opinion was the role of psychological treatments. Just $25 \%$ of respondents agreed that methylphenidate should only be used where psychological therapies had failed to produce sufficient impact. Opinion was divided regarding the statement that methylphenidate should only be used as an adjunct to, or to facilitate, psychological therapies.

Prescribing issues are shown in Table 3. There was agreement $(83 \%)$ that responses to methylphenidate should initially be monitored with rating scales completed by parents and teachers. In terms of dosage frequency, $85 \%$ of respondents usually prescribed methylphenidate twice daily. The maximum frequency was three times daily. Most respondents $(54 \%)$ disagreed that there are children who need methylphenidate in doses greater than $60 \mathrm{mg}$ daily.

Many respondents (71\%) considered that methylphenidate should not usually be given continuously (i.e. including weekends and school holidays). In association with this, $83 \%$ agreed that once a year methylphenidate should be withdrawn gradually to see if it is still needed. Several respondents added that this depended on individual cases and exacerbating situational factors.

\section{Comment}

The main finding is a strong consensus that methylphenidate is useful in hyperkinetic disorder, and may be useful for some (but not all) children with ADHD. This suggests that clinicians' use of medication will continue to increase as the views of clinical leaders disseminate. One view is that only a child mental health service is in the position to carry out the necessary assessment of children, parents and family systems with differential diagnosis and baseline psychometry. Prescribing, on this view, should be only one part of a comprehensive treatment programme that has access to psychological therapies, and can liaise with schools regarding educational interventions. Another view is that some paediatricians have a particular interest and expertise in the area, and should be able to initiate treatment. It may be more constructive to focus on this rather than to restrict prescribing to psychiatrists. Currently there are regions where there are insufficient child psychiatrists to meet parental demand, and some are not expert in prescribing. Some respondents suggested that particular subgroups should be the domain of child psychiatrists, for example children outside the 6-13 year age-range, or where there is comorbidity with learning disability. Tourette's syndrome, pervasive developmental disorders or anxiety states. 
Table 3. Methylphenidate prescribing issues $(n=24)$

\begin{tabular}{lccc}
\hline Statement & Agree & Disagree & Don't know \\
\hline $\begin{array}{l}\text { There are children who need more } \\
\text { than } 60 \text { mg daily }\end{array}$ & $7(29 \%)$ & $13(54 \%)$ & $4(17 \%)$ \\
$\begin{array}{l}\text { Initial monitoring by parent and teacher } \\
\quad \text { rating scales }\end{array}$ & $20(83 \%)$ & $4(17 \%)$ & 0 \\
$\begin{array}{l}\text { Should usually be given continuously } \\
\text { Withdrawn annually to see if it is still needed }\end{array}$ & $5(21 \%)$ & $17(71 \%)$ & $2(8 \%)$ \\
\hline
\end{tabular}

Although there was support for methylphenidate as a first-line treatment in some instances, there was conflicting opinion about the role of adjunctive psychological treatments. This may particularly be the case in clear hyperkinetic disorder and/or if parents' and schools' management is already acceptable. It was also acknowledged that in some cases psychological treatment may be difficult to implement or may be insufficient. Some respondents emphasised the importance of psychological treatments both in the broadest sense (i.e. reframing, advice, support) and in more precise methods (e.g. parent training, social skills training, and expressed emotion interventions), particularly in comorbid cases.

The development of consensus guidelines for treating hyperactivity can proceed in the knowledge that UK experts show much agreement on the case for using stimulant medication. Guidelines will need to take into account the dosage range to be used, the significance of comorbidity, and the roles of other professionals who are involved in ongoing management. The role of paediatricians in initiating treatment is not clear, and it would be helfpul to canvass their views.

\section{Acknowledgements}

We thank Professor Peter Hill for helpful comments on the original draft of the questionnaire. We also thank all the respondents for their replies and comments. They are: Dr V. F. A. Bailey, Thelma Golding Centre, Hounslow; Dr D. Black, Traumatic Stress Clinic, London; Prof. D. J. Cottrell, University of Leeds; Prof. A. D. Cox, Guy's and St Thomas' UMDS; Prof. E. Garralda, Imperial College School of Medicine at St Mary's; Dr R. Goodman, Institute of Psychiatry; Prof.
I. M. Goodyer, University of Cambridge; Prof. R. C. Harrington, University of Manchester; Prof. J. W. Hill, University of Liverpool; Prof. P. D. Hill, St George's Hospital Medical School; Dr P. Hoare, Royal Hospital for Sick Children, Edinburgh; Dr B. Lask, Great Ormond Street Hospitals; Dr P. A. McArdle, Fleming Nuffield Unit, Newcastle-uponTyne; Dr M. Murphy, Gartnavel Royal Hospital, Glasgow; Prof. A. R. Nicol, University of Leicester; Prof. W. Ll. Parry-Jones, University of Glasgow; Prof. J. B. Pearce, University of Nottingham; Dr M. Prendergast, Great Ormond Street Hospitals; Prof. M. Rutter, Institute of Psychiatry; Dr S. Sandberg, Royal London Hospital; Dr C. Sturge, Northwick Park Hospital; Dr M. J. Thompson, Ashurst Hospital, Southampton; Dr J. Turk, St George's Hospital Medical School; and Dr M. Wieselberg, Middlesex Hospital.

\section{References}

AMERICAN PSYCHIATRIC ASSOCLATION (1994) Diagnostic and Statistical Manual of Mental Disorders (4th edn) (DSMIV). Washington, DC: APA.

CONSUMERS' ASSOCIATION (1995) The management of hyperactive children. Drug and Therapeutic Bulletin. 33, 57-60.

SANDBERG, S. (1996) Hyperkinetic or attention deficit disorder. British Journal of Psychiatry, 169, 10-17.

TAYLOR, E. \& HEMSLEY, R. (1995) Treating hyperkinetic disorder in childhood. British Medical Journal, $\mathbf{3 1 0}$. 1617-1618.

*Kapil Sayal, Registrar, Bethlem and Maudsley Hospitals, London SE5 8AZ; and Eric Taylor, Professor of Developmental Neuropsychiatry. MRC Child Psychiatry Unit, London SE5 8AF

*Correspondence 